\title{
UNUSUAL TRAUMATIC DEFORMITY OF THE LENS*
}

\author{
BY \\ P. SIVASUBRAMANIAM \\ Victoria Memorial Eye Hospital, Colombo, Ceylon
}

THE most bizarre pattern of lesions may accompany ocular injury. When the violence is severe, damage may amount to complete disruption of the globe. When the violence is moderate, the integrity of the globe may be preserved though the structures within it may be irreparably damaged. Severe intra-ocular haemorrhage or a total lental opacity may cloud the clinical picture. In the latter case a deformity of the lens is of little moment as in any event the opaque lens has to be removed to restore sight. A fairly transparent lens with a deformity, while permitting some kind of visual function, is a clinico-optical problem. The following case is of interest as a curious lental deformity presenting unique clinical features.

\section{Case Report}

A 12-year-old boy met with an accident due to the premature explosion of a fire-cracker. He was admitted to the Victoria Memorial Eye Hospital, Colombo, at 8 p.m. on April 8, 1957 , with the lower right lid torn at the mid-point and a flaccid perforated right globe. There was a lacerated penetrating wound with a tongue-shaped corneal flap at about 5 o'clock, and the rupture extended about $2 \mathrm{~mm}$. on to the sclera through which a portion of the iris had prolapsed. The pupil was deformed and a hyphaema filled the lower fifth of the anterior chamber. The lens appeared clear. An emergency operation was performed at once under gas and oxygen anaesthesia. The prolapsed iris was excised, the wound trimmed and sutured, and the torn lower lid repaired. Atropine drops and penicillin ointment were used post-operatively and the boy made an uneventful recovery as regards the rupture of the globe. $X$-ray examination of the globe did not reveal any foreign body (though metal casings are sometimes used by unscrupulous firework manufacturers in Ceylon).

Examination at the end of a week revealed a quiet eye and the visual acuity was $1 / 60$. Indirect ophthalmoscopy showed the fundus reflex to be divided into two by a straight line passing obliquely from about 9 to 4 o'clock. The part of the fundus below the line appeared slightly greyish in colour, which led at first to a suspicion of a retinal detachment, while the area above it appeared to be the usual pinky-red. On extreme infraduction the fundus showed a red crescentic glow. On direct ophthalmoscopy these appearances were seen to be due to a fold on the lens capsule and not to a retinal detachment.

Retinoscopy presented a complex phenomenon. . Above the oblique line the shadow was "plus" vertically and "minus" transversely, while below the line both shadows were "plus". With the following correction , $+2 \mathrm{D}$ sph., $-3.25 \mathrm{D}$ cyl. axis $90^{\circ}$, the visual acuity in the injured eye was $6 / 36$.

Biomicroscopy revealed a "buckling" of the posterior lental surface at about the junction of the middle and lower thirds. This buckling was produced by an obliquely placed traction fold which glistened in oblique illumination. The fold was in the

* Received for publication October 10, 1957. 
posterior capsule, and close to it were faint "rosette" opacities (Figs 1 and 2). The lens measured $4.2 \mathrm{~mm}$. above and $2.8 \mathrm{~mm}$. below the fold (Fig. 3).

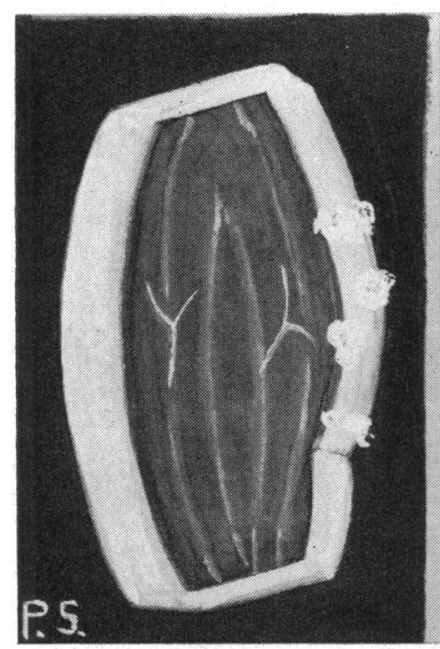

FIG. 1.-Fold in posterior lens capsule and rosette opacities in posterior cortex shown by the broad beam of the slit lamp.

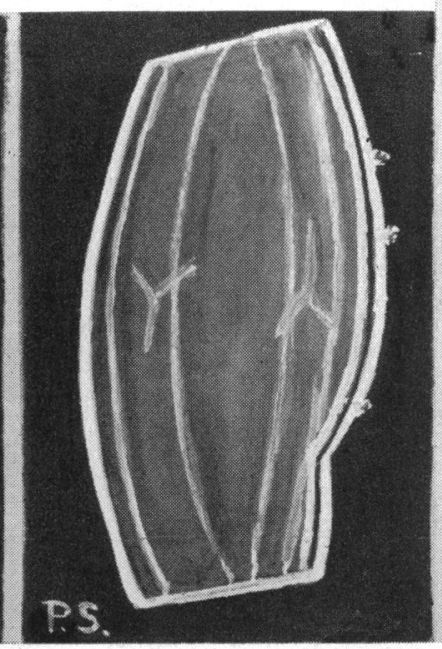

Fig. 2.-Optical section shown by the narrow beam of the slit lamp.

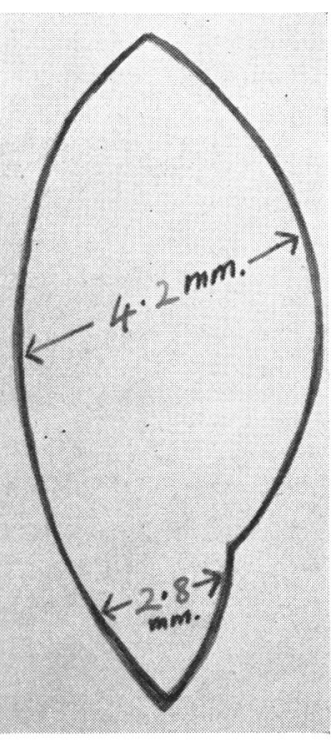

FIG. 3.-Measurements with Ulbrich's drum attached to the slit-lamp microscope, showing the thickness of the lens above and below the deformation.

\section{Comment}

Bignell (1951) described two cases of folds in the lens capsule after trauma and suggested that they were caused by a partial rupture of the zonule. In this case, however, the appearance was that of a traction fold, the capsule being made taut along a certain line owing to deformation of the ciliary ring, so that at two opposite points the zonule exerted an equal and opposite pull pinching up the capsule into a fold. The disposition of the site of rupture and the near coincidence of the traction fold along the same axis lends support to the idea that the fold is caused by a deformation of the ciliary ring. That such a fold can exist without a rupture of the capsule is exemplified by the commonplace procedure of grasping the anterior capsule with intracapsular forceps at the commencement of an intracapsular extraction of the lens. Besides this the folds in Bignell's cases were loose, as can be seen in the drawings of the slit-lamp microscopic appearances reproduced in his paper.

My thanks are due to Dr. W. H. V. Ferdinands, surgeon-in-charge of the Victoria Memorial Eye Hospital, for permission to publish this case and to Dr. D. Muttucumarane for her help with the notes.

\section{REFERENCE}

Bignell, J. L. (1951). Brit. J. Ophthal., 35, 234. 